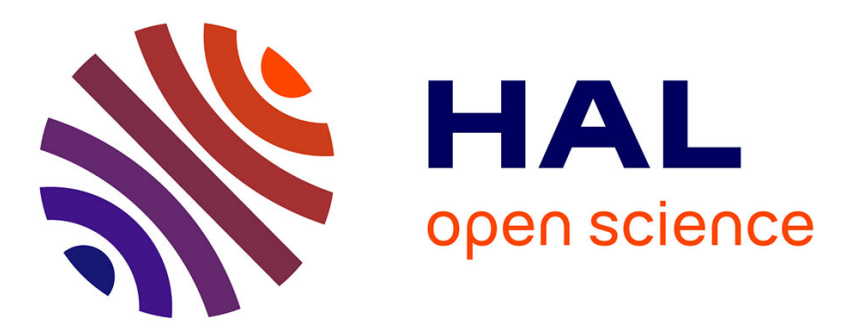

\title{
Adsorption of EOR chemicals under laboratory and reservoir conditions, part II: Bacterial reduction methods
}

H. Wayne Harris, Régis Grimaud, D. Levitt

\section{- To cite this version:}

H. Wayne Harris, Régis Grimaud, D. Levitt. Adsorption of EOR chemicals under laboratory and reservoir conditions, part II: Bacterial reduction methods. SPE Asia Pacific Enhanced Oil Recovery Conference,, 2015, Kuala Lumpur, Malaysia. pp.702-716. hal-01614787

\author{
HAL Id: hal-01614787 \\ https://hal.science/hal-01614787
}

Submitted on 11 Jan 2018

HAL is a multi-disciplinary open access archive for the deposit and dissemination of scientific research documents, whether they are published or not. The documents may come from teaching and research institutions in France or abroad, or from public or private research centers.
L'archive ouverte pluridisciplinaire HAL, est destinée au dépôt et à la diffusion de documents scientifiques de niveau recherche, publiés ou non, émanant des établissements d'enseignement et de recherche français ou étrangers, des laboratoires publics ou privés. 


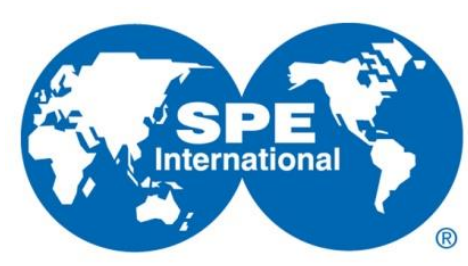

SPE-174636-MS

\title{
Adsorption of EOR chemicals under laboratory and reservoir conditions, Part II: Bacterial reduction methods
}

\author{
H. Wayne Harris ${ }^{1}$, Regis Grimaud ${ }^{2}$, and David Levitt ${ }^{3}$
}

\author{
1 University of Southern California (currently at Laurence Livermore National Laboratories) \\ 2 Equipe Environnement et Microbiologie - Université de Pau, France \\ 3 Total E\&P, France \\ Copyright 2015, Society of Petroleum Engineers
}

This paper was prepared for presentation at the SPE Enhanced Oil Recovery Conference held in Kuala Lumpur, Malaysia, 11-13 August 2015.

This paper was selected for presentation by an SPE program committee following review of information contained in an abstract submitted by the author(s). Contents of the paper have not been reviewed by the Society of Petroleum Engineers and are subject to correction by the author(s). The material does not necessarily reflect any position of the Society of Petroleum Engineers, its officers, or members. Electronic reproduction, distribution, or storage of any part of this paper without the written consent of the Society of Petroleum Engineers is prohibited. Permission to reproduce in print is restricted to an abstract of not more than 300 words; illustrations may not be copied. The abstract must contain conspicuous acknowledgment of SPE copyright.

\section{Abstract}

We have successfully performed bacterial reduction of an iron-containing outcrop sand sample under static conditions using Shewanella genus bacteria. Adsorption of an anionic (alkyl benzyl sulfonate) surfactant was around 7-times lower on treated outcrop samples. Most of this reduction $(\sim 3 \mathrm{X})$ occurs over the first 3-4 days of incubation, contemporaneously with iron dissolution and limited biofilm formation. Continued incubation after this point attends the formation of significant biofilm, as well as a continued decrease in surfactant adsorption. Non-iron-reducing bacteria also formed biofilm on outcrop samples, yielding a significant (though smaller) decrease in surfactant adsorption. Microscopy demonstrates preferential attachment of biofilm to iron minerals in a heterogenous outrop sample. Repeated rinsing results in a removal of biofilm formed by iron-reducing or bacteria and a corresponding increase in surfactant adsorption to about $1 / 3$ to $1 / 2$ of original levels.

This proof of concept for a bacterial core restoration method using iron-reducing bacteria is considered successful, with the caveat that care must be taken to minimize and/or remove biofilm in order to avoid biofilm-related artifacts. Implications of these results for the determination of reservoir rock-fluid properties in biologically-active reservoirs are also discussed.

\section{INTRODUCTION}

The confounding role of iron oxidation in surfactant adsorption measurements, first identified by Wang in 1993 [1], is presented in detail in Part I of this investigation [2].

Following the observation of surfactant adsorption up to 6 times less than expected during the Loudon microemulsion flooding pilots, Wang demonstrated that the oxidizing conditions in laboratory cores could explain the discrepancy [1]. Wang and Guidry went on to document the role of oxidation-reduction potential in governing core wettability [3]. Though a crude simplification, the oxidation of iron (II) to iron (III) in the clay matrix, in minerals, or adsorbed on one of the two, may be thought of as yielding a more positively-charged surface, increasing affinity for anionic species such as the most common EOR 
surfactants and polymers, as well as acidic components of crude oils [4]. Stucki has rigorously documented this effect on the cation exchange capacity (CEC) of iron-rich smectites [1]. The high specific surface area of iron oxyhydroxides compared to iron(II) minerals may represent a significant additional reactive surface, as suggested in Part I. Surfactant consumption is often identified as having among the greatest impacts on project economics in sensitivity studies [2]. In the carbonate milieu, surfactant consumption may be an even greater driver.

It has been previously demonstrated that oxidation-reduction state of porous media also strongly affects other surface properties, including the adhesion of polar species in crude oils, and hence wettability [3]. Thus the ability to understand and manipulate the iron mineralogy and oxidation-reduction character of cores may also help resolve open questions relating to wettability establishment and alteration, and by extension "low-sal" water flooding mechanisms.

\section{Current methods for reducing cores}

Despite the discrepancies revealed by Wang's work, reduction of core samples before chemical EOR corefloods continues to be the exception rather than the rule. The predominant method for reduction, when this is performed, is with sodium dithionite, a very strong yet highly unstable reducing agent that, unfortunately, also evolves acid during its rapid aqueous decomposition. For this reason, a buffer (typically sodium bicarbonate) is commonly used to prevent the dissolution of clays and calcite. A chelating agent increases the rate of iron dissolution, and methods have been proposed using either citrate [5] or EDTA [6] in combination with sodium dithionite and sodium bicarbonate for the restoration of clays and core samples, respectively. However under these conditions, it is likely that in addition to iron reduction, significant iron removal, is occurring [2]. Partial or total removal of iron-containing minerals may result in an artificially-low surfactant adsorption. Wang notes that adsorption of surfactants on individual clay minerals is lower after treatment with dithionite than under preserved, anaerobic conditions, and that this change is not completely reversible with subsequent reoxidation [1]. At the same time, while sodium bicarbonate, citrate, and/or EDTA are introduced to aid in the iron removal process, studies have not yet been conducted to determine whether the use of these chemicals introduces any additional artifacts.

In addition to reducing structural iron in clays, an ideal core reduction process would also remineralize atmospherically-oxidized ferric oxides as the reduced forms more representative of those found in the reservoir, such as magnetite, pyrite, and siderite, rather than just elude them as soluble Fe(II).

\section{Dissimilatory metal reducing bacteria (DMRB)}

Many microorganisms capable of reducing metal oxyhydroxides have been characterized and isolated. Organisms of the genus Shewanella are particularly well suited for metal reducing applications of this kind because because they are facultative anaerobes, which means that they can grow under both aerobic and anaerobic conditions and oxidize a variety of carbon sources [7-11]. The methods for cultivating Shewanella spp. are reliable and reproducible, and can be accomplished by a non-microbiologist. Lactate is often chosen as carbon source and electron donor because it maximizes the energy released per mole in oxidation reactions, and is optimal for metal reduction reactions [12-15]. While over 200 Shewanella spp have been identified, the species Shewanella putrefacians CN32 stands out for its high iron reduction kinetics and robustness in a wide range of conditions [30]. The genome of strain CN32 is fully sequenced, annotated, and available online.

Optimal incubation temperature for Shewanella putrefacians $\mathrm{CN} 32$ has been determined to be $30^{\circ} \mathrm{C}$ based on growth rate experiments $[16,17]$. However, other thermophilic Shewanella spp have been isolated and are available depending on application requirements. CN32 is capable of growth in a wide variety of saline conditions from 1 to $30 \%$ [18]. The presence of other microbes does not inhibit CN32 metal reduction except by electron donor/ substrate competition [19-21]. The CN32 strain can reduce many metals, including $\mathrm{Fe}(\mathrm{III}), \mathrm{Co}(\mathrm{III}), \mathrm{U}(\mathrm{VI}), \mathrm{Cr}(\mathrm{VI})$, and $\mathrm{Tc}(\mathrm{VII})$, and the $\mathrm{Fe}(\mathrm{III})$ reduction kinetics 
have been previously characterised [22]. The starting crystal structure and composition of iron oxyhydroxide minerals has been shown to effect the bacterial reduction kinetics of Fe(III) [23, 24].

\section{Secondary mineral formation and other mineral interactions}

Secondary mineral formation (biomineralisation) during bacterial reduction of iron oxyhydroxides can be influenced by the $\mathrm{pH}$, buffer, buffer concentration, and species. Under static conditions, Shewanella strains have been demonstrated to reduce iron oxides to siderite (in presence of $\mathrm{HCO}_{3}{ }^{-}$) [25], pyrite (in presence of $\mathrm{H}_{2} \mathrm{~S}_{/} \mathrm{SO}_{4}{ }^{-}$), or magnetite $[23,26]$. The ability to biomineralize siderite and pyrite is of particulary interest, as these one or both of these minerals often predominate in reservoir environments. One simple way to achieve this may be the introduction of various amounts of bicarbonate buffer into the growth media [8]. The original carbon source also influences the mineral produced [27]. In some cases it has also been that different Shewanella species produce different secondary minerals, likely because varying metal reduction kinetics (i.e. slow vs. fast reduction) influence mineral formation [26]. More than $90 \%$ of structural iron (III) in smectites can be reduced to iron (II) by Shewanella oneidensis MR-1 [28]. Under dynamic flow conditions, Shewanella can remove amorphous ferrihydrite from untreated hematite surfaces, causing it to be eluded as Fe(II). Living Shewanella MR-1 inhibits calcite dissolution, preventing the formation of etch pits, while a dead biofilm does not. The $\mathrm{pH}$ does not decrease, suggesting the bacteria may be using the carbon and preventing transport of $\mathrm{CO}_{2}$ into solution [29]. Bacterial reduction of $\mathrm{Fe}$ (III)-containing clays alters the structure of clay and reduces smectite minerals, and HFO in reactive flow $[28,30]$. The kinetics of bacterial reduction of iron bearing smectite minerals has previously been characterized [28, 31-33].

\section{Motivation for this study}

As discussed above, reproducing the reducing conditions present in oil reservoirs in a laboratory containing ubiquitous oxygen is a fundamental challenge in studies relating to reservoir surface chemistry. Iron reducing bacteria may allow for a cost effective and environmentally friendly solution to this challenge. While undoubtably more complex than chemical methods, bacterial reduction methods have the potential to avoid some of the complications associated with the use of strong chemical cocktails containing reducing agents like sodium dithionite, such as polymer degradation upon subsequent oxygen exposure, as well as perhaps unintended artifacts of exposure to these chemicals. While existing chemical treatement methods likely result in the removal of iron-contaning minerals (with the possible exception of structural iron in clays), a bacterial method has the potential to remineralize iron oxyhydroxides as Fe (II) minerals such as pyrite and siderite. Bacterial treatment methods may thus result in an iron mineral assemblage closer to that originally established by bacterial-mediated deposition or alteration of iron in-situ in petroleum reservoirs.

\section{METHODS}

\section{Cultivation and strains:}

Shewanella putrefaciens CN-32, Pseudomonas fluorescens, Shewanella oneidensis MR-1 and non-iron reducing deletion mutants originating from MR-1 were examined in this study. All cultures and mineral outcrop incubation experiments used a previously described defined minimal medium (M1), containing $18 \mathrm{mM}$ lactate as an energy source [34] (See Appendix). Strains were inoculated from freezer stock onto Luria-Bertani (LB) plates and then grown overnight at $30^{\circ} \mathrm{C}$. Individual colonies were then selected and inoculated into defined minimal media and grown overnight (M1). The cells were then harvested at 0.5 optical density (OD) at $600 \mathrm{~nm}$ and then spun at 5,500 rpm for $20 \mathrm{~min}$ at $20^{\circ} \mathrm{C}$. All strains were then resuspended in $150 \mu \mathrm{l}$ of minimal media and then added to insoluble outcrop mineral sample (15 g), and $20 \mathrm{ml}$ of media in $50 \mathrm{ml}$ Falcon tubes (VWR International LLC, Randor, Pennsylvania, USA) and incubated horizontally in a shaker $\left(180 \mathrm{rpm}\right.$ ) for $1-7$ days at $30{ }^{\circ} \mathrm{C}$ (Amerex Instruments, Lafayette, California, USA). Anaerobic samples are incubated on revolving wheel at $10 \mathrm{rpm}$ inside an anaerobic 
chamber (Coy Laboratory Products Inc, Grass Lake, Michigan, USA).

\section{Defined Minimal Media:}

Was prepared according to protocol in Harris et al, 2012 [35]. Initially $\mathrm{NaOH}$ is added to $1 / 4$ the working volume of the solution and PIPES buffer is dissolved into solution. Lactate can be highly viscous and is therefore weighed in a Teflon weight dish. Vitamins, minerals and amino acids cannot be autoclaved. Instead these are filtered through a sterile 0.22 micron filter in a sterile hood and then added to media after cooling the autoclaved solution.

\section{Preparation and sterilization of outcrop samples:}

A loosely consolidated sandstone sample was collected from an East-African lacustrine outcrop. The sample was disaggregated, homogenized, and sieved using a $1.6 \mathrm{~mm}$ sieve to remove large particles and debris. Untreated samples were analysed by XRD, XRF, Mössbauer spectroscopy and SEM-XRD. Mineral composition as determined by combination of XRD and XRF is presented in Table 1. Initial experiments were performed both with and without initial sterilization of samples. Bacterial iron reduction was measurable during both competitive culture and monoculture conditions, however sterilized samples underwent more rapid and extensive reduction (unpublished data). Samples used in the remainder of this study were thus first sterilized in excess $70 \%$ isopropyl alcohol and then dried in $60^{\circ} \mathrm{C}$ until all isopropyl had evaporated.

\section{HFO preparation:}

$\mathrm{Fe}(\mathrm{OH})_{3}$ stock solution was prepared according to the protocol by Cornell and Schwertmann [36].

\section{Biofilm washing:}

Two types of washing procedures were used to remove biofilm; DI-vortex wash, and DI-acid-vortex wash. For the DI vortex procedure, the mineral sample was prepared using the above adsorption protocol and once dry, $10 \mathrm{ml}$ of DI water was added to mineral and the solution vortexed for 60 seconds, then the liquid was disposed of after treatment with a $30 \%$ bleach solution. This cycle, including vortex, was repeated 2 additional times. For the DI acid treatment the procedure was identical except the first rinse contained $10 \mathrm{mM}$ of acidic acid and the solution was allowed to sit with the sample for $15 \mathrm{~min}$. Then the remaining two rinses contained only DI $\mathrm{H}_{2} \mathrm{O}$.

\section{Surfactant Adsorption Protocol:}

All surfactant adsorption experiments were made using an alkylbenzenesulfonate (P550, Cepsa Quimica). Sand samples are first dried for 2 hours in a $60^{\circ} \mathrm{C}$ drying oven. Then sample is then weighed and divided into four $15 \mathrm{ml} \mathrm{Falcon}$ tubes. Each tube contained $\sim 500 \mathrm{mg}$ of sample, with the precise weight recorded. $6 \mathrm{~mL}$ of surfactant solution is then added, with concentration varying from 250 to $1500 \mathrm{ppm}$. Initial adsorption measurements were performed after only one hour of sample equilibration. These measurements correspond to Figures 2, 4, and 6. It was later realized that adsorption of P550 on the outrop sample continues to increase for up to 16 hours, and so far greater equilibration times are necessary to obtain a steady, repeatable value. Figure 3 corresponds to measurements made after 16 hours of equilibration.

Following equilibration, each tube is subjected to vortex for 30 seconds and then spun in centrifuge (Heraeus Multifuge X3, Thermo Scientific, Waltham, MA, United States of America) at $5500 \mathrm{rpm}$ for 20 $\min$ at $20^{\circ} \mathrm{C}$. The sample is then filtered with a 2 micron syringe filter (Millex-GP, Darmstadt, Germany) and adsorption is measured in the $240-300 \mathrm{~nm}$ wavelength range by Ultraviolet spectrophotometer (Uvikon, Serlabo Technologies, Entraigues sur la Sergue, France). The peak near 262 is recorded and the concentration of surfactant is calculated based on a standard curve. 


\section{Crystal violet biofilm assay:}

Solid fraction is removed from incubation sample and air dried at $60^{\circ} \mathrm{C}$ for 1 hour. $\sim 700 \mathrm{mg}$ of the solid sample is then placed into one well of a 26 well $(3 \mathrm{ml})$ plate. Crystal violet stain is added to each sample well $(125 \mu \mathrm{l})$ and mixture is vortexed for 10 seconds. The sample well is then washed 10 times with $1 \mathrm{ml}$ of DI water. Then each sample is incubated with $200 \mu \mathrm{l}$ of acidic acid (1M) and allowed to sit for $15 \mathrm{~min} .125 \mu \mathrm{l}$ is then added to sterile DI water to total $1000 \mu \mathrm{l}$, and then placed in spectrophotometer cuvette. Absorbance is measured by spectrophotometer at $560 \mathrm{~nm}$ wavelength.

\section{Hach-Lange iron measurement (Kit method):}

The procedure described by the Hach-Lange kit for measurement range of 0.005 to $2 \mathrm{mg} / \mathrm{l}$ was followed (LCW 021, Hach-Lange GMBH, Düsseldorf, Germany). Performed standard curve to generate concentration values and initial measurements were verified by HPLC/IC. The samples were first spun at $5,500 \mathrm{G}$ for $20 \mathrm{~min}$ at $20^{\circ} \mathrm{C}$. Then inside an anaerobic chamber, each $5 \mathrm{ml}$ sample was filtered using a 0.22 micron filter syringe and added to spectrophotometer cuvette. Cuvettes must be thoroughly cleaned with iron free distilled water and $30 \% \mathrm{HCl}$ before using. $0.2 \mathrm{ml}$ of acid reagent $\mathrm{A}$ is mixed in with sample by pipetting and then allowed to sit for 3 minutes. Then $0.3 \mathrm{ml}$ of buffer solution $\mathrm{B}$ is mixed in with the sample solution. Iron-trace microcap containing ferrozine ${ }^{\mathrm{tm}}$ is then added and mixed by inversion. After 15 minutes, the absorbance of the sample at $560 \mathrm{~nm}$ is measured in spectrophotometer. Special care is taken to avoid air bubbles in the bottom of the cuvette.

\section{Ferrozine Measurement of ferrous and ferric iron:}

Colorimetric ferrozine (PDT disulfonate; 3-[2-Pyridyl]-5,6-diphenyl-1,2,4-triazine-4,4'-disulfonic acid) was dissolved in $50 \mathrm{mM}$ HEPES buffer and balanced to $\mathrm{pH} 7$ at a concentration of $0.05 \% \mathrm{wt} / \mathrm{vol}$. The ferrozine solution is then used before one month to prevent degradation. The sample is centrifuged for 20 min at 10,000 rpm to remove all Fe(IV) and then mixed with equal volumes of saturated (1M) $\mathrm{HCl}$. A separate sample with solid $\mathrm{Fe}(\mathrm{IV})$ is mixed with equal parts saturated hydroxylamine/ $\mathrm{HCl}$ solution. The acidified sample is then mixed by vortex for 10 seconds and incubated at $60^{\circ} \mathrm{C}$ for 2 hours. Then $300 \mu 1$ of acidified sample is transferred into $700 \mu \mathrm{l}$ of ferrozine solution. Absorbance was measured in spectrophotometer (Novaspec Plus, Amerisham Biosciences, Little Chalfont, United Kingdom) at $562 \mathrm{~nm}$ using a $1 \mathrm{ml}$ semi-micro cuvette (Ratiolab, Dreieich, Germany). This method has been adapted from Stucki et al 2006 [32].

\section{SEM Preparation:}

Outcrop samples are removed and immediately fixed aerobically using $2 \%$ glutaraldehyde solution. Sand is separated from liquid media with sterile metal scapula and then gently flushed ( $1 \mathrm{ml}$ added then removed) with $\mathrm{pH} 7 \mathrm{PBS}$. The samples are then flushed with 50\% phosphate-buffered saline (PBS), and then sterile deionized water. Samples are then inundated with $500 \mu \mathrm{l}$ ethanol, then allowed to dry for 30 min (in 10\%, 50\%, and then $100 \%$ concentrations of ethanol. The samples are then placed in a vacuum chamber overnight. The dried samples were coated with gold and then viewed by using a Zeiss-LEO 982 FE-SEM. The preparation protocol was modified from Gorby et al 2006 [37].

\section{RESULTS:}

Cells attached preferentially to iron oxyhydroxides minerals in a heterogeneous outcrop sample By using a combination of fluorescence and brightfield Apatome ${ }^{\mathrm{TM}}$ microscopy we determined the location of bacterial cells on minerals (Figure 1A and B). This analysis revealed that cells attach to $\mathrm{Fe}(\mathrm{OH})_{3}$ in density of 1.5 cells/micron ${ }^{2}$. The cells did not appear attached to silica particles or other noniron oxyhydroxides containing minerals in the outcrop sample. The iron-oxide containing minerals were characterized by a distinctive red/brown color, while other minerals appeared clear or dark black without color. Non metal reducing bacteria strains, Pseudomonas fluorescens and $\Delta$ cymA (non-iron-reducing 
deletion mutant) did not attach to the iron oxyhydroxide containing mineral in high numbers $(<0.05$ cells/micron ${ }^{2}$ ), florescence microscopy image in SI (Figure S1A and S1B).

High numbers of CN32 cells were also found to attach to surface of HFO after 7 days of incubation (SI Figure 2). However, cells did not appear to attach directly to Si mineral surface, as in the case of incubations with Ottawa sand, and Sikasol sand samples.

\section{Biofilm increases through time}

Over a 10 day incubation period in presence of outcrop core sample, it was found that both CN32 and non-metal reducing deletion mutant $(\Delta$ cymA) yielded measurable levels of biofilm increase (Figure $2 \mathrm{~A}$ ). It was also verified that high absorbance measures from crystal violet biofilm assays strongly correlated with high number of cells attached to minerals (data not shown). Measurements of biofilm also are significant in incubations with wild type (WT) CN32 with HFO, Ottawa sand, and iron-rich outcrop samples (discussed below). After around 9 days, biofilm detection drops precipitously. This may be due to nutrient depletion.

\section{Iron reduction in outcrop sample by CN32 and MR-1 incubation:}

Bacterial reduction of iron oxyhydroxides in outcrop samples was established by an increase in Fe(II) concentration from $8 \mu \mathrm{M}$ initially to $270 \mu \mathrm{M}$ after 10 days of incubation in anaerobic conditions. Significant iron reduction $(>200 \mu \mathrm{M})$ is detectable after only 3 days of incubation with CN32 strain. Low levels of iron reduction $(<100 \mu \mathrm{M})$ occured after 7 days of incubation with deletion mutant strain $\Delta$ cymA. Abiotic HFO and outcrop samples soaked in sterile distilled water resulted in $2 \mu \mathrm{M}$ and $7 \mu \mathrm{M}$ of iron dissolution, respectively. Similar abiotic 7 day long control experiments with an iron-rich subsample of the East-African lacustrine outcrop resulted in $19 \mu \mathrm{M}$ of iron dissolution. Samples incubated with $\mathrm{CN} 32$ bacteria strain for 7 days resulted a maximum of $313 \mu \mathrm{M}$ of iron dissolution. Full chemical reduction of core revealed that bacterial reduction (by $\mathrm{CN} 32$ ) reduces almost $45 \%$ of total iron chemically-reducible iron (Hach-Lange Ferrozine method).

\section{Bacterial treatment of outcrop sample lowers adsorption of anionic surfactant:}

Adsorption of an anionic, alkyl benzyl sulfonatesurfactant on outcrop samples was lower following 1 to 10 day bacterial treatment with Shewanella CN32, and surfactant adsorption decreased with additional treatment time, as illustrated in Figure 3. Treatment with non-metal reducing strains $P$. fluorescence and Shewanella deletion mutant $(\triangle$ cymA $)$ also resulted in significant decreases in surfactant adsorption, however not to the same extent as with CN32 strain incubations (Figure 4). The adsorption of $1500 \mathrm{ppm}$ surfactant was lowered by $39 \%$ and $63 \%$ following 10-day incubation with P. fluorescence and deletion mutant $(\Delta$ cymA), respectively. By comparison, surfactant adsorption was lowered by $97 \%$ in an outcrop sample incubated with CN32 strain under these conditions. The total adsorption of all strains with multiple surfactant concentrations is shown in Figure 2C and 3. The correlation coeffiecient of iron reduction and adorption reduction is high (0.96) while correlation coefficient of adsorption with biofilm is relatively weak (0.45). This confirms that a portion of the decrease in surfactant adsorption is due to the formation of a biofilm, while a portion is due to iron reduction.

\section{More biofilm formation occurs on iron-containing minerals than on non-iron containing minerals}

As shown in Figure 1, CN32 attached selectively to iron containing particles over Si containing particles. Biofilm formation was measured by crystal violet spectrophotometric assay following incubation of CN32 with core samples with various amounts iron. These included a sample of lab-prepared hydrous ferrous oxide (HFO), a visibly iron-rich sub-sample of outcrop rock, a homogenized outcrop rock sample, and Ottawa sand. Biofilm assay decreased with iron content, with HFO>iron-rich outcrop sample>homogenized outcrop sample>Ottowa sand. 


\section{Biofilm flush protocol reduces biofilm while maintaining adsorption benefits}

Washing of bacterial treated samples by a dionized water (DI) flush and vortex regimen are compared to a $10 \mathrm{mM}$ acidic acid $\left(\mathrm{CH}_{3} \mathrm{COOH}\right)$ and DI flush with vortex regimen. The DI flush, reduced the quantity of biofilm down the level of the abiotic control, while DI/acidic acid protocol reduced biofilm measure only slightly more significantly. The adsorption of surfactant on treated outcrop samples flushed with either DI or $\mathrm{HCl}$ increased significantly, but remained 53-64\% lower than untreated sample and abiotic control (Figures 5 and 6).

\section{DISCUSSION}

\section{Correlation between iron reduction and adsorption:}

Comparison of iron reduction, adsorption and biofilm during 10 day incubation of CN32 strain with outcrop sample is shown in Figure 2D. The majority of adsorption decrease occurs during an early period when iron reduction is evident, and little biofilm has formed. This decrease may be due to the reduction of structural iron in clays or the removal of high-specific surface area iron oxides. The reduction of structural iron in smectites by Shewanella bacteria has already been demonstrated by Kosta (1999)[28], with measurable effects on surface properties such as cation exchange capacity (CEC). The effect of high surface area iron oxides, as suggested in part I of this investigation, is another possible explanation for this change.

\section{Effect of biofilm on surface properties:}

The aim of this study was to perform the proof of concept of a bacterial restoration method for core and outcrop samples for use in reservoir studies. In addition to the desired effect of iron reduction on surfactant adsorption, a second effect, correlated to the formation of biofilm, was seen in samples incubated with either iron-reducing or non-iron-reducing bacteria for extended periods. Fortunately, iron reduction is quick (2-3 days) compared to the time required for significant biofilm formation ( $>3$ days), and preliminary evidence suggest that even after 10 days of incubation biofilm can be easily removed by repeated rinsing.

Many potential avenues for additional process refinement exist. As mentioned above, brine composition may be manipulated to prevoke deposition of desired secondary minerals such as siderite or pyrite [25]. Previous studies have defined and characterized the phases of biofilm formation in Shewanella oneidensis MR-1 and identified some influencing factors associated with biofilm growth [38]. Biofilm formation in other species has been shown to be dependent upon initial wettability of the sand/sediment [39]. In addition, the original structure of smectite, quartz and HFO mineral is a determining factor in Shewanella biofilm formation[40]. Carbon limitation of Shewanella spp. has been shown to enhance the dispersal of cells through a core sample [41]. Further control of biofilm formation in Shewanella may be possible through the addition of soluble electron acceptors or carbon sources [42].

In addition to a proof of concept for a bacterial core restoration method, the above results suggest a significant and almost entirely unexplored effect that native bacteria may have on reservoir surface properties, particularly in biologically-active reservoirs. Our results suggest that biofilm formed by ironreducing bacteria may have a stronger effect on surface properties than non-iron-reducing bacteria, possibly due to their preferential adhesion to high-energy sites of iron mineralization. However, the effect of biofilm formation on surfactant adsorption was significant for non-iron reducing bacteria as well. Previous results have demonstrated that biofilm can effect rock properties such as diffusivity [43, 44]. Our results suggest that rock-fluid properties such as relative permeability may be influenced by the presence of biofilm as well.

\section{Adsorption on treated and untreated outrop samples}

It should be noted that there is significant variability in absolute adsorption measurements of alkyl benzyl sulfonate (ABS) surfactant on outcrop samples, even prior to treatment. Plateau adsorption varies 
between 9 and $19 \mathrm{mg} / \mathrm{g}$ of rock. Specific surface area of this outcrop rock was measured by BET, and found to be $6.4 \mathrm{~m}^{2} / \mathrm{g}$, however, as will be discussed in a subsequent article, this value has since been found to decrease significantly with rinsing. Some of this variability may be due to slight differences in sample preparation. For example it was determined after initial experiments that the kinetics of surfactant adsorption on the outcrop sample were relatively slow, taking around 16 hours to reach equilibrium. This may explain why initial measurements made after only 1 hour show lower adsorption, whereas later measurements, performed after at least 16 hours of equilibration, yield higher measurements. Using the highest value measured $(19 \mathrm{mg} / \mathrm{g})$ and assuming a bilayer of adsorbed surfactant, we obtain a molecular parking area (MPA) of $38 \AA^{2} /$ molecule. Using the lowest value would suggest only a monolayer of adsorbed molecules, and a MPA of $41 \AA^{2} /$ molecule. As discussed in Part I, calculation and previous measurements suggest that a dense packing of sulfonate surfactants leads to a MPA of $33-40$

$\AA^{2} /$ molecule. Thus while some uncertainty may remain regarding the nature of the adsorbed layer (monolayer or bilayer), it is clear that a strong attractive interaction occurs between ABS and untreated outcrop material. This would be unusual on pure quartz sand, where electrostatic repulsion between negatively-charged quartz surfaces and anionic surfactants typically result in negligible adsorption, hence the attractiveness of anionic chemicals in clastic reservoirs. However, the outcrop sample studied is decidedly unpure, consisting of just over 50\% quartz, and large amounts of feldspars, iron-containing minerals, and clays.

After 3 days of incubation, at the point where most reduction has taken place but significant biofilm has not yet formed, ABS adsorption decreases to around $6 \mathrm{mg} / \mathrm{m}^{2}$. This suggests an adsorbed monolayer, and based on the above-mentioned pretreatment specific surface area, a MPA of $61 \AA^{2} /$ molecule. However post-treatment specific surface area was not measured and it is likely that this value decreased somewhat from the treatment process, so this value is likely overestimated.

\section{Conclusions}

- We have successfully performed bacterial reduction of an iron-containing outcrop sand sample under static conditions using Shewanella bacteria;

- Microscopy indicates preferential attachement of Shewanella CN32 to iron minerals in a heterogeneous outcrop sample;

- Adsorption of an anionic (alkyl benzyl sulfonate) surfactant was around 7-times lower on treated outcrop samples. Some of this decrease was contemporaneous with measured iron reduction, and some of it occurred during a later period of significant biofilm growth;

- Biofilm can be removed by simple rinsing techniques, yielding a corresponding partial increase in surfactant adsorption;

- This proof-of-concept for a bacterial core restoration method using iron-reducing bacteria is considered successful, with the caveat that care must be taken to minimize and/or remove biofilm in order to avoid biofilm-related artifacts.

- The preceeding results suggest that the presence of biofilm in petroleum reservoirs may have a hitherto unaccounted effect on surface properties such as surfactant adsorption and wettability.

\section{Acknowledgements}

The authors wish to express their gratitude Total for allowing us to publish this article. The authors would also like to thank Antony Ranchou-Peyruse, Ken Nealson, Eric Gaucher, Danielle Morel, Maurice Bourrel, Matthieu Loriau, and Alexandra Klimenko for helpful discussions, and Arantxa Camus Etchecopar, for assistance in the laboratory.

\section{References:}


1. Wang, F., Effects of reservoir anaerobic, reducing conditions on surfactant retention in chemical flooding. SPE reservoir engineering, 1993. 8(2): p. 108-116.

2. Levitt, D., Adsorption of EOR Chemicals under Laboratory and Reservoir Conditions, Part 1Iron Abundance and Oxidation State. IOR 2015-18th European Symposium on Improved Oil Recovery, 2015.

3 Wang, F.H. and Guidry,L.J., Effect of oxidation-reduction condition on wettability alteration. SPE Formation Evaluation, 1994. 9(2): p. 140-148.

4. $\quad$ Stucki, J., Chapter 8: Iron redox processes in smectites. Handbook of Clay Science (eds. F. Bergaya, BKG Theng, G. Lagaly), Elsevier, Amsterdam, 2005.

5. Mehra, O. P., and M. L. Jackson. "Iron oxide removal from soils and clays by a dithionite-citrate system buffered with sodium bicarbonate." National conference on clays and clays minerals. Vol. 7. 1958.

6. Rajapaksha, S., Restoration of Reservoir Cores to Reservoir Condition before Chemical Flooding Tests. SPE Improved Oil Recovery Symposium, 2014.

7. Nealson, K.H. and C.R. Myers, Microbial reduction of manganese and iron: new approaches to carbon cycling. Applied and Environmental Microbiology, 1992. 58(2): p. 439.

8. $\quad$ Fredrickson, J.K., et al., Biogenic iron mineralization accompanying the dissimilatory reduction of hydrous ferric oxide by a groundwater bacterium. Geochimica et Cosmochimica Acta, 1998. 62(19-20): p. 3239-3257.

9. Myers, C.R. and K.H. Nealson, Bacterial manganese reduction and growth with manganese oxide as the sole electron acceptor. Science, 1988. 240(4857): p. 1319-21.

10. Venkateswaran, K., et al., Shewanella amazonensis sp. nov., a novel metal-reducing facultative anaerobe from Amazonian shelf muds. International Journal of Systematic Bacteriology, 1998. 48(3): p. 965-972.

11. Gao, H., et al., Shewanella loihica sp. nov., isolated from iron-rich microbial mats in the Pacific Ocean. International Journal of Systematic and Evolutionary Microbiology, 2006. 56(8): p. 19111916.

12. Burdige, D.J., et al., Fluxes of dissolved organic carbon from California continental margin sediments. Geochimica et cosmochimica acta, 1999. 63(10): p. 1507-1515.

13. Fredrickson, J.K., et al., Towards environmental systems biology of Shewanella. Nat Rev Microbiol, 2008. 6(8): p. 592-603.

14. Serres, M.H. and M. Riley, Genomic analysis of carbon source metabolism of Shewanella oneidensis MR-1: Predictions versus experiments. Journal of Bacteriology, 2006. 188(13): p. 4601-4609.

15. Tang, Y.J., A.L. Meadows, and J.D. Keasling, A kinetic model describing Shewanella oneidensis $M R$ - 1 growth, substrate consumption, and product secretion. Biotechnology and bioengineering, 2007. 96(1): p. 125-133.

16. Abboud, R., et al., Low-temperature growth of Shewanella oneidensis MR-1. Applied and Environmental Microbiology, 2005. 71(2): p. 811-816.

17. Gao, H., et al., Global transcriptome analysis of the heat shock response of Shewanella oneidensis. Journal of Bacteriology, 2004. 186(22): p. 7796-7803.

18. Paulick, A., et al., Two different stator systems drive a single polar flagellum in Shewanella oneidensis MR - 1. Molecular microbiology, 2008. 71(4): p. 836-850.

19. Nealson, K.H., Sediment bacteria: Who's there, what are they doing, and what's new? Annual Review of Earth and Planetary Sciences, 1997. 25: p. 403-434.

20. Magot, M., B. Ollivier, and B.K. Patel, Microbiology of petroleum reservoirs. Antonie van Leeuwenhoek, 2000. 77(2): p. 103-116.

21. Hau, H.H. and J.A. Gralnick, Ecology and biotechnology of the genus Shewanella. Annu. Rev. Microbiol., 2007. 61: p. 237-258.

22. Liu, C., et al., Reduction kinetics of Fe (III), Co (III), U (VI), Cr (VI), and Tc (VII) in cultures of 
dissimilatory metal- reducing bacteria. Biotechnology and Bioengineering, 2002. 80(6): p. 637649.

23. Salas, E.C., Studies on the influence of bacteria and carbon source on the products of dissimilatory iron reduction. 2008: ProQuest.

24. Kostka, J.E., et al., Reduction of structural Fe (III) in smectite by a pure culture of Shewanella putrefaciens strain MR-1. Clays and Clay Minerals, 1996. 44(4): p. 522-529.

25. Liu, C., et al., Kinetic analysis of the bacterial reduction of goethite. Environmental Science \& Technology, 2001. 35(12): p. 2482-2490.

26. Salas, E.C., et al., The impact of bacterial strain on the products of dissimilatory iron reduction. Geochimica et Cosmochimica Acta, 2010. 74(2): p. 574-583.

27. Salas, E.C., et al., The influence of carbon source on the products of dissimilatory iron reduction. Geomicrobiology Journal, 2009. 26(7): p. 451-462.

28. Kostka, J.E., et al., The impact of structural Fe (III) reduction by bacteria on the surface chemistry of smectite clay minerals. Geochimica et Cosmochimica Acta, 1999. 63(22): p. 37053713.

29. Lüttge, A. and P.G. Conrad, Direct observation of microbial inhibition of calcite dissolution. Applied and environmental microbiology, 2004. 70(3): p. 1627-1632.

30. Kostka, J.E., et al., Respiration and dissolution of iron (III)-containing clay minerals by bacteria. Environmental Science \& Technology, 1999. 33(18): p. 3127-3133.

31. Kim, J., et al., Role of microbes in the smectite-to-illite reaction. Science, 2004. 303(5659): p. 830-832.

32. Stucki, J.W. and J.E. Kostka, Microbial reduction of iron in smectite. Comptes Rendus Geoscience, 2006. 338(6): p. 468-475.

33. Bose, S., et al., Bioreduction of hematite nanoparticles by the dissimilatory iron reducing bacterium Shewanella oneidensis MR-1. Geochimica et Cosmochimica Acta, 2009. 73(4): p. 962976.

34. Bretschger, O., et al., Current Production and Metal Oxide Reduction by Shewanella oneidensis MR-1 Wild Type and Mutants. Applied and Environmental Microbiology, 2007. 73(21): p. 70037012.

35. H. Wayne Harris, M.Y.E.N.a.K.H.N., Shewanella oneidensis MR-1 chemotaxis proteins and electron-transport chain components essential for congregation near insoluble electron acceptors. Biochemical Society Transactions 2012. 40(6): p. 1167-1177.

36. Schwertmann, U. and R.M. Cornell, Iron oxides in the laboratory. 2008: John Wiley \& Sons.

37. Gorby, Y.A., et al., Electrically conductive bacterial nanowires produced by Shewanella oneidensis strain MR-1 and other microorganisms. Proceedings of the National Academy of Sciences of the United States of America, 2006. 103(30): p. 11358-11363.

38. Thormann, K.M., et al., Initial phases of biofilm formation in Shewanella oneidensis MR-1. Journal of Bacteriology, 2004. 186(23): p. 8096-8104.

39. Huggett, M.J., B.T. Nedved, and M.G. Hadfield, Effects of initial surface wettability on biofilm formation and subsequent settlement of Hydroides elegans. Biofouling, 2009. 25(5): p. 387-399.

40. Alimova, A., et al., Effects of smectite clay on biofilm formation by microorganisms. Biofilms, 2006. 3(1): p. 47-54.

41. Cunningham, A.B., et al., Effects of starvation on bacterial transport through porous media. Advances in Water Resources, 2007. 30(6-7): p. 1583-1592.

42. Thormann, K.M., et al., Control of formation and cellular detachment from Shewanella oneidensis MR-1 biofilms by cyclic di-GMP. Journal of bacteriology, 2006. 188(7): p. 2681-2691.

43. Woodruff, S., et al., The effects of a developing biofilm on chemical changes across the sedimentwater interface in a freshwater environment. International review of hydrobiology, 1999. 84(5): $\mathrm{p}$. 509-532.

44. De Beer, D., et al., Effects of biofilm structures on oxygen distribution and mass transport. 
Biotechnology and bioengineering, 1994. 43(11): p. 1131-1138.

Table 1: Mineralogical analysis of outcrop sample

Mineral Mass \%

\begin{tabular}{l|l}
\hline Quartz & 56.5 \\
\hline
\end{tabular}

\begin{tabular}{l|r} 
Albite & 18.4 \\
\hline
\end{tabular}

\begin{tabular}{l|l} 
Microcline & 9.5 \\
\hline
\end{tabular}

\begin{tabular}{l|l}
\hline Jarosite & 5.0 \\
\hline
\end{tabular}

\begin{tabular}{l|l}
\hline Apatites & 0.8
\end{tabular}

\begin{tabular}{l|l}
\hline Anatase & 0.8
\end{tabular}

\begin{tabular}{l|l} 
Pyrite & 0.7 \\
\hline
\end{tabular}

\begin{tabular}{l|l}
\hline Barite & 0.2 \\
\hline
\end{tabular}

\begin{tabular}{l|l}
\hline Calcite & 0.0 \\
\hline
\end{tabular}

Micas and/or Illite $\quad 6.0$

\begin{tabular}{l|l}
\hline Smectite & 2.0
\end{tabular}

Total Clays \& micas: $\quad 8.0$ 

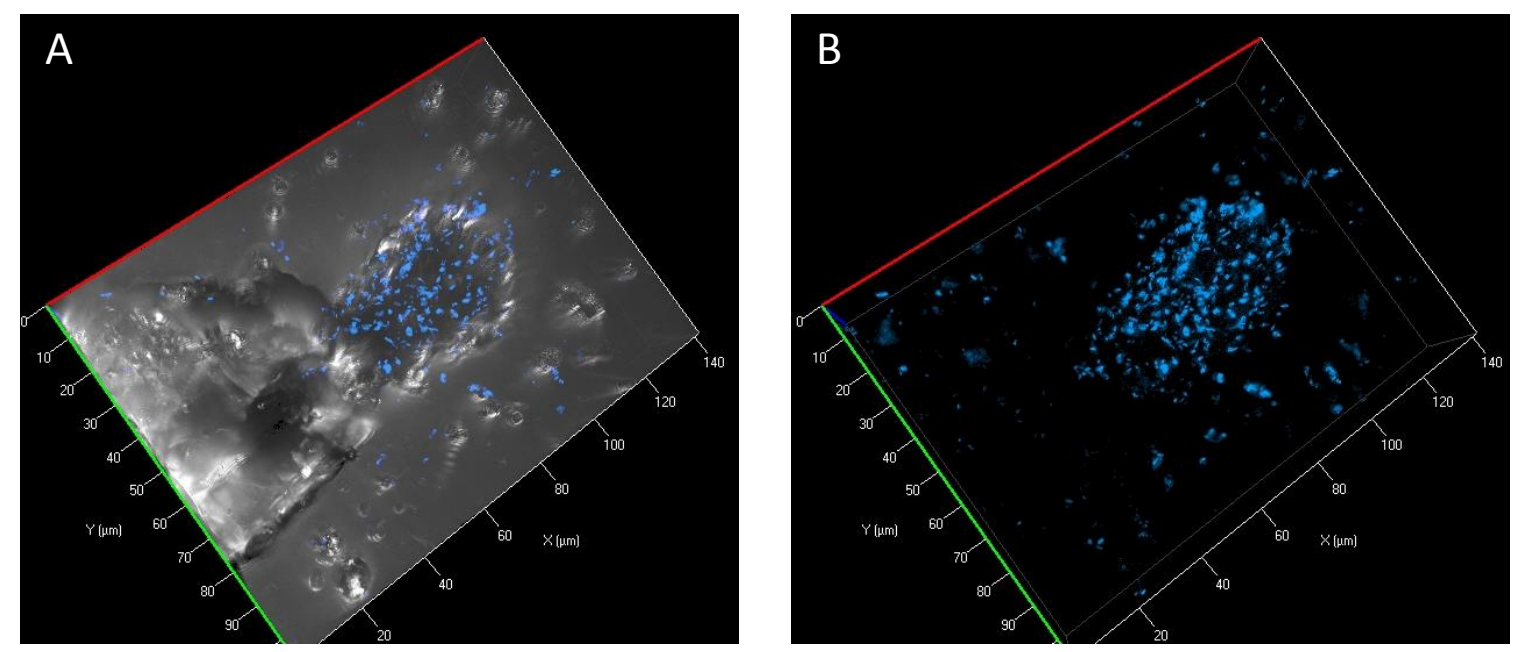

Figure 1A and B - 3D image of Shewanella putrefaciens CN32 bacteria cells (blue) attached to iron oxyhydroxides (center) but not silica (left center). Brightfield image overlayed with fluorescense image (A) of DAPI stained cells in 3 dimensions. Sand particles appear to be clear on the left side of (A) while iron oxyhydroxides appear darker in colour (center). The right image (B) shows only fluorescent image of DAPI stained cells with the black scale bar on the right $=40 \mu \mathrm{m}$.
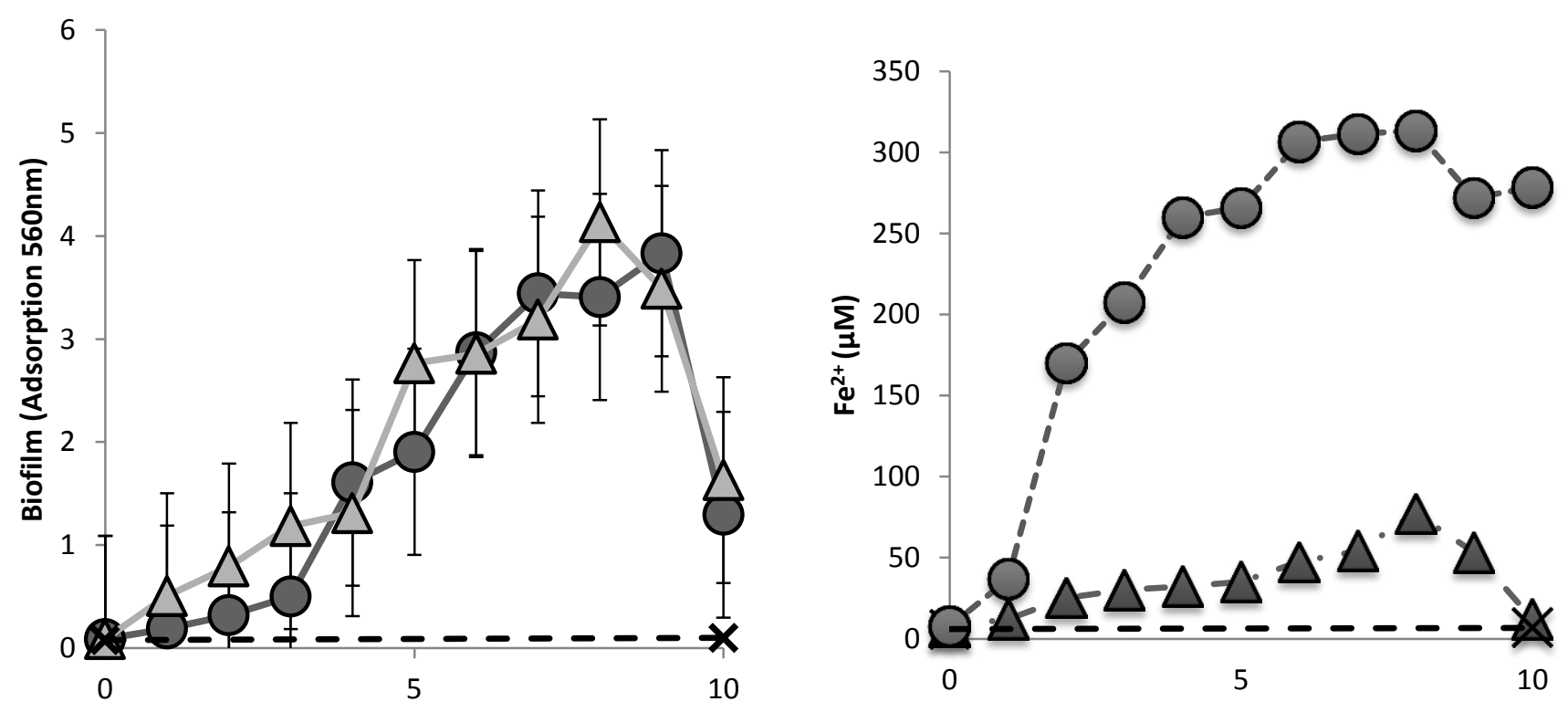


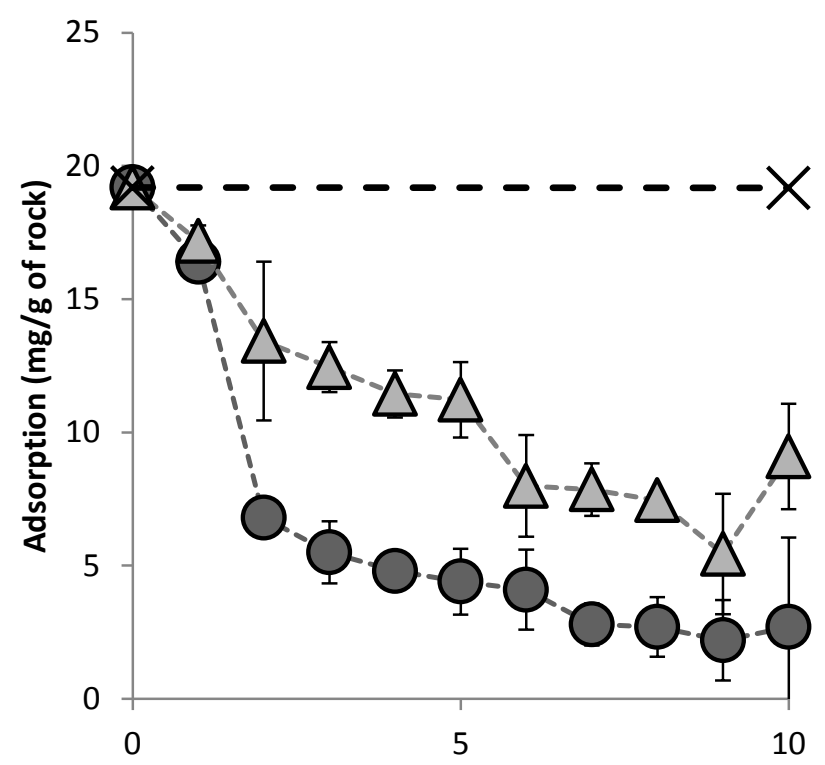

Figure 2ABC - Biofilm, iron reduction and adsorption of bacterial treated outcrop samples over 10 day period. (A) Measure of biofilm (Absorbance at $560 \mathrm{~nm}$ ) in WT CN32 strain $(\bullet)$ and $\Delta$ cymA, non-metal reducing deletion mutant $(\Delta)$ compared to abiotic control $(X)$. While (B) shows iron reduction (Fe2+ $\mathrm{mg} / \mathrm{L}$ ) in $\mathrm{CN} 32(\bullet), \Delta$ cymA $(\Delta)$ and abiotic control $(\mathrm{X})$. The outcrop sample then shows significant reduction in adsorption of $1500 \mathrm{ppm}$ surfactant $(\mathrm{g} / \mathrm{mg}$ of rock) in bacterial treated samples, both in WT ( $\square$ ) and mutant $(\Delta)$ but not in abiotic control $(\mathrm{X})$.

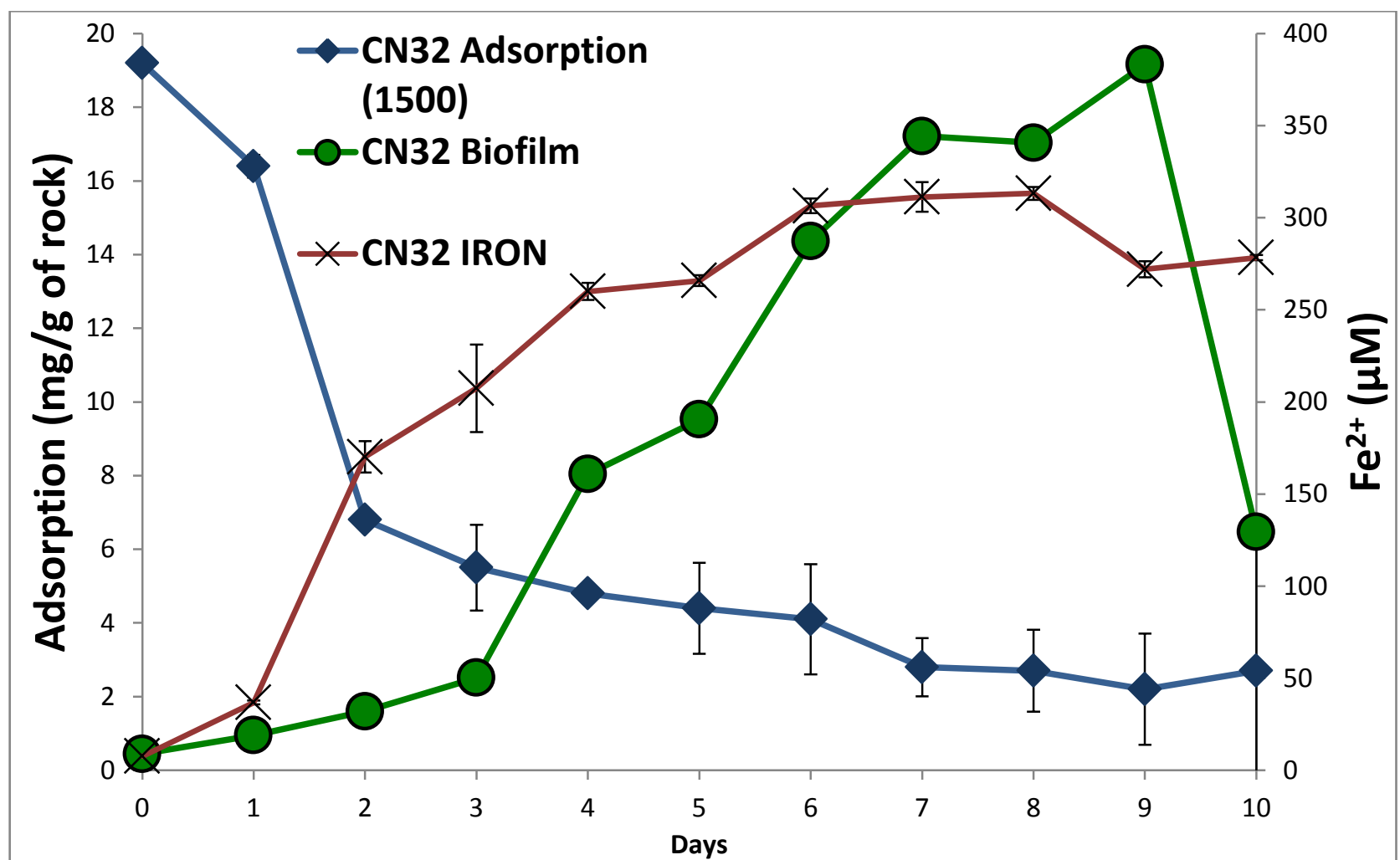

Figure 3 Wild type CN32 bacteria biofilm, iron reduction and adsorption over 10-day treatment. Alkyl benzyl sulfonate (ABS), initial concentration of $1500 \mathrm{ppm}$, adsorption $(\diamond)$ decrease is initially correlated with with iron reduction $(X)$, but continued decrease occurs during the period of biofilm formation ( $\square$ ). 


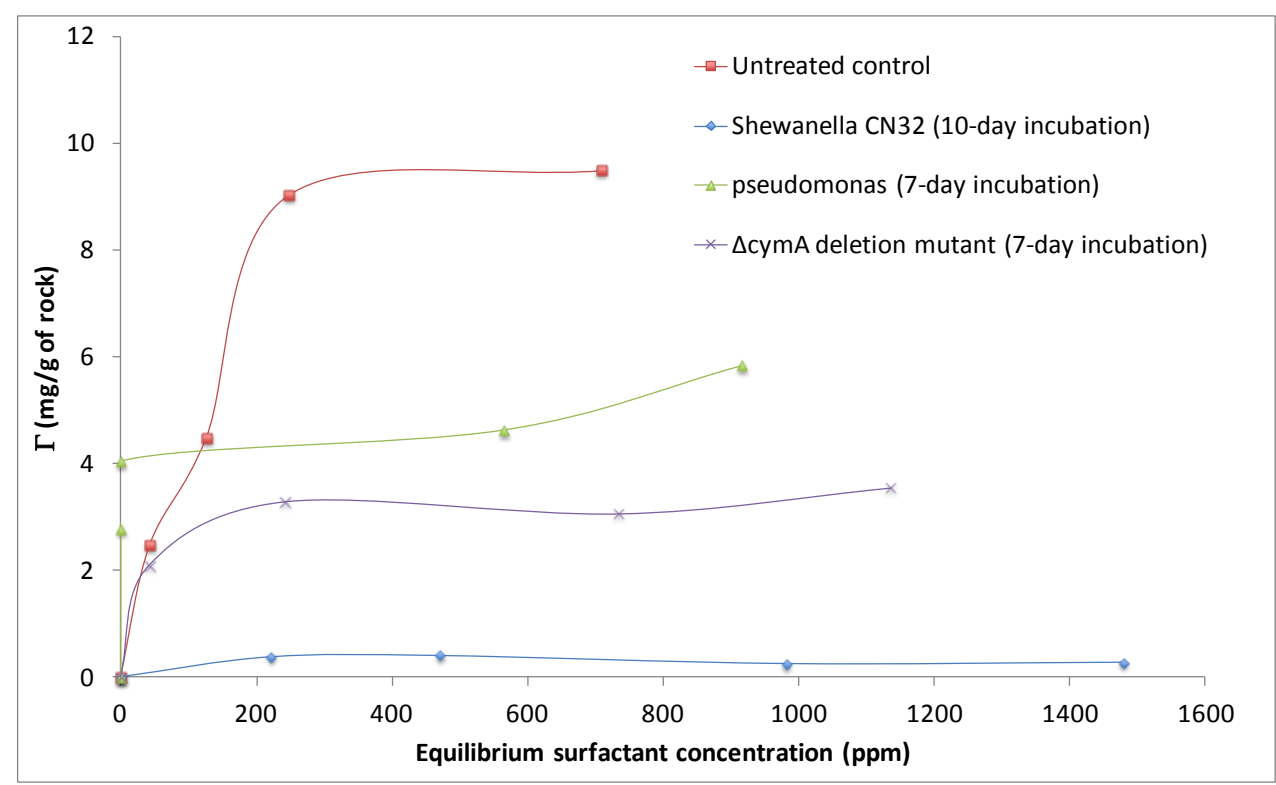

Figure 4 - Alkyl benzyl sulfonate adsorption isotherms before and after bacterial treatments.

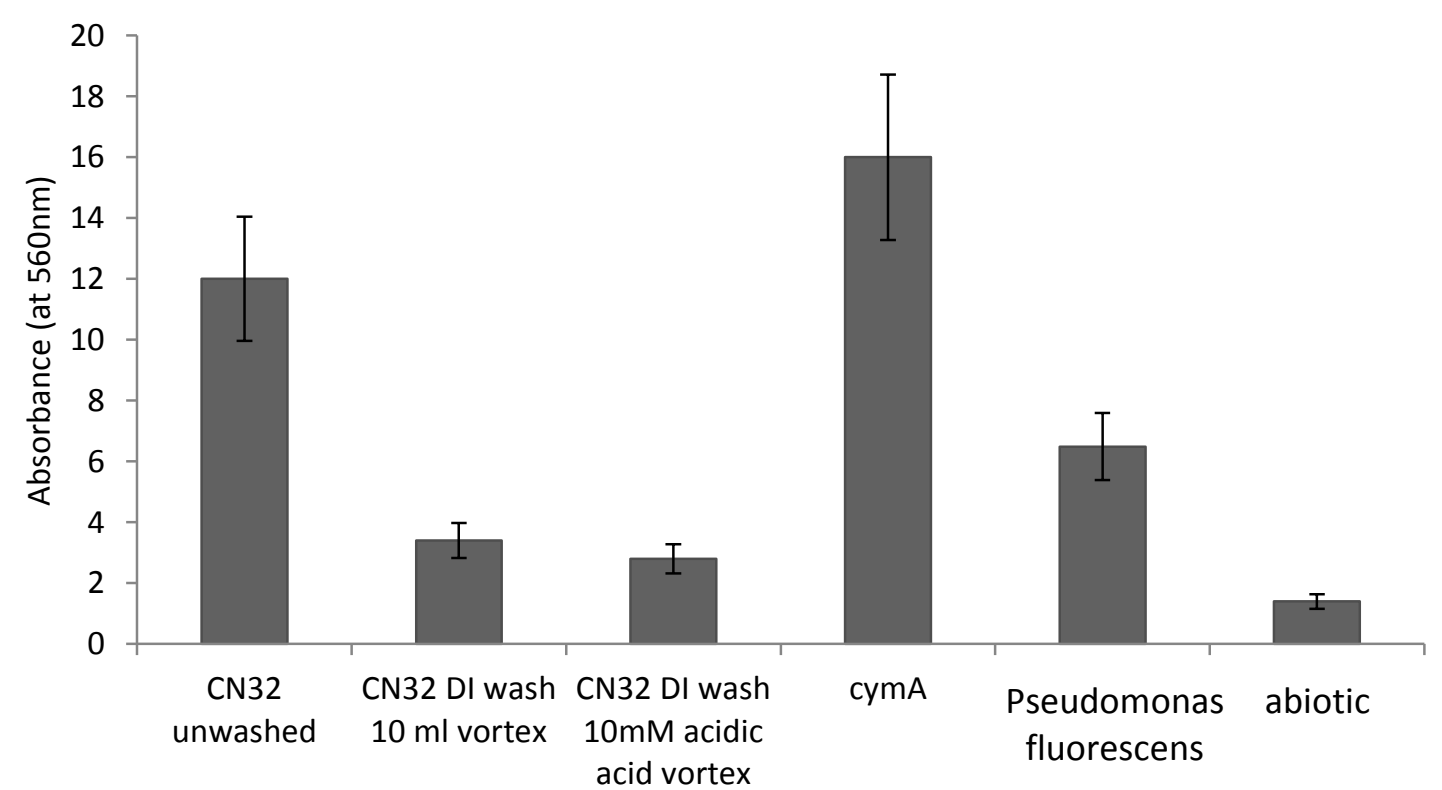

Figure 5. Biofilm measure after various flush protocols performed on outcrop samples incubated with bacteria strains $C N 32, \Delta$ cym A, or Pseudomonas fluorescens. 


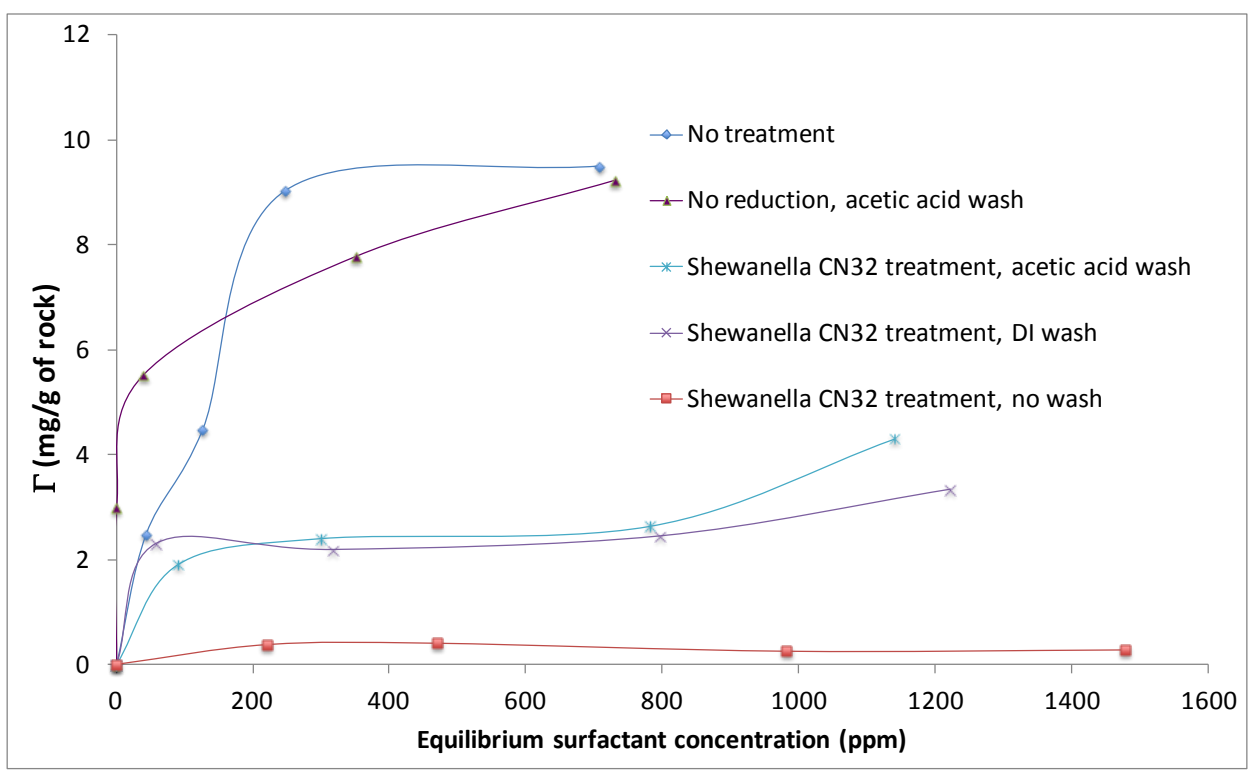

Figure 6 - Alkyl benzyl sulfonate adsorption isotherms after various biofilm removal procedures. 


\section{Appendix}

Table S1. Composition of media

(a) MR-1 minimal medium

\section{Chemical description}

Pipes buffer

Sodium hydroxide

Ammonium chloride

Potassium chloride

Sodium phosphate monobasic, monohydrate

Vitamin solution, $100 \times$ stock

Amino acid solution, $100 \times$ stock

Mineral solution, $100 \times$ stock

Sodium lactate, $60 \%$ (w/w) syrup

\section{(b) Vitamin solution}

\section{Chemical description}

Biotin (D-biotin)

Folic acid

Pyridoxine $\mathrm{HCl}$

Riboflavin

Thiamine $\mathrm{HCl}$

Nicotinic acid

D-Pantothenic acid, hemicalcium salt

Vitamin $\mathrm{B}_{12}$

p-Aminobenzoic acid

Thioctic acid ( $\alpha$-lipoic acid)

\section{Supplier and catalogue} number

Sigma P-1851

Sigma S-5881

Sigma A-5666

Sigma P-4504

Sigma S-9638

See below

See below

See below

Sigma L-1375

Supplier and catalogue number

Sigma B-4639

Sigma F-7876

Sigma P-9755

Sigma R-4500

Sigma T-4625

Sigma N-4126

Sigma P-2250

Sigma V-2876

Sigma A-9878

Sigma T-5625
Final concentration in medium (mM)

50

7.5

28.04

1.34

4.35

18

Final concentration in medium (nM)

81.87

45.34

486.38

132.84

140.73

406.17

209.82

0.74

364.62

242.37 
(c) Amino acid solution

\section{Chemical description}

L-Glutamic acid

L-Arginine

DL-Serine

(d) Mineral solution

\section{Chemical description}

Nitrilotriacetic acid (dissolve with $\mathrm{NaOH}$ to $\mathrm{pH} 8$ )

Magnesium sulfate

heptahydrate

Manganese sulfate

monohydrate

Sodium chloride

Ferrous sulfate heptahydrate

Calcium chloride dihydrate

Cobalt chloride hexahydrate

Zinc chloride

Cupric sulfate pentahydrate

Aluminium potassium

disulfate dodecahydrate

Boric acid

Sodium molybdate dihydrate

Nickel chloride hexahydrate

Sodium tungstate

\section{Concentration of} $100 \times$ stock $(\mathrm{g} / \mathrm{l})$

2

2

2

\section{Supplier and catalogue number}

Sigma N-9877

Aldrich 23,039-1

Aldrich 22,128-7

Sigma S-3014

Sigma F-8633

Sigma C-3881

Sigma C-3169

Sigma Z-3500

Sigma C-6283

Sigma A-7167

Sigma B-6768

Aldrich 22,184-8

Sigma N-6136

Sigma S-0765
Supplier and catalogue Final concentration in number medium (mg/l)

Sigma G-1251 2

Sigma A-3909 2

Sigma S-4375 2

Final concentration in medium $(\mu \mathrm{M})$

78.49

121.71

29.58

171.12

3.60

6.80

4.20

9.54

0.40

0.21

1.62

1.03

1.01

0.76

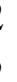

